\title{
Increases in the abundance of microbial genes encoding halotolerance and photosynthesis along a sediment salinity gradient
}

\author{
T. C. Jeffries ${ }^{1,2}$, J. R. Seymour ${ }^{2}$, K. Newton ${ }^{1}$, R. J. Smith ${ }^{1}$, L. Seuront ${ }^{1,3,4}$, and J. G. Mitchell ${ }^{1}$ \\ ${ }^{1}$ School of Biological Sciences, Flinders University, Adelaide, South Australia 5001, Australia \\ ${ }^{2}$ Plant Functional Biology and Climate Change Cluster, University of Technology Sydney, Australia \\ ${ }^{3}$ Aquatic Sciences, South Australian Research and Development Institute, Henley Beach 5022, Australia \\ ${ }^{4}$ Centre National de la Recherche Scientifique, Paris cedex 16, France
}

Correspondence to: T. C. Jeffries (jeffries.thomas@gmail.com)

Received: 14 July 2011 - Published in Biogeosciences Discuss.: 28 July 2011

Revised: 30 January 2012 - Accepted: 31 January 2012 - Published: 20 February 2012

\begin{abstract}
Biogeochemical cycles are driven by the metabolic activity of microbial communities, yet the environmental parameters that underpin shifts in the functional potential coded within microbial community genomes are still poorly understood. Salinity is one of the primary determinants of microbial community structure and can vary strongly along gradients within a variety of habitats. To test the hypothesis that shifts in salinity will also alter the bulk biogeochemical potential of aquatic microbial assemblages, we generated four metagenomic DNA sequence libraries from sediment samples taken along a continuous, natural salinity gradient in the Coorong lagoon, Australia, and compared them to physical and chemical parameters. A total of 392483 DNA sequences obtained from four sediment samples were generated and used to compare genomic characteristics along the gradient. The most significant shifts along the salinity gradient were in the genetic potential for halotolerance and photosynthesis, which were more highly represented in hypersaline samples. At these sites, halotolerance was achieved by an increase in genes responsible for the acquisition of compatible solutes - organic chemicals which influence the carbon, nitrogen and methane cycles of sediment. Photosynthesis gene increases were coupled to an increase in genes matching Cyanobacteria, which are responsible for mediating $\mathrm{CO}_{2}$ and nitrogen cycles. These salinity driven shifts in gene abundance will influence nutrient cycles along the gradient, controlling the ecology and biogeochemistry of the entire ecosystem.
\end{abstract}

\section{Introduction}

Biogeochemical cycles, over geological time, have fundamentally determined the chemical nature of the Earth's surface and atmosphere. Due to their high abundance and metabolic activities, microorganisms drive many global biogeochemical processes including the carbon, oxygen, nitrogen, hydrogen, sulfur and iron cycles (Falkowski et al., 2008; Fuhrman, 2009). The biochemical potential of the microbial inhabitants of an environment is determined by the community structure - the types of organisms present and their relative abundance, which is in turn largely determined by the physico-chemical conditions of the habitat, such as the need for cells to survive in highly saline environments by adjusting their internal salt concentrations (Oren, 2009). How microbial communities respond to and contribute to chemical gradients is a central question of microbial ecology and is essential to our understanding of biogeochemical cycling and biological adaptation to global change.

Salinity has an important influence on the global distribution of bacterial diversity (Lozupone and Knight, 2007). Salinity gradients occur in a wide variety of ecologically important habitats such as estuaries, wetlands, salt marshes and coastal lagoons. Many of these habitats are under increasing pressure from climate change, due to increased evaporation, reduced freshwater flows, and rising sea levels (Scavia et al., 2002; Schallenburg et al., 2003).

In high salinity environments, microbes must maintain their cellular osmotic balance via the acquisition of charged solutes (Roberts, 2005; Oren, 2009). This fundamental physiological requirement has led to the evolution of 
halotolerant specialists, with several studies in hypersaline habitats demonstrating that microbial diversity decreases with salinity (Estrada et al., 2004; Schapira et al., 2010; Pedrós-Alió et al., 2000; Benlloch et al., 2002) with halotolerant and halophilic taxa becoming dominant in more extreme salinities. Shifts in microbial community structure have also been observed along estuaries (Bouvier and del Giorgio, 2002; Oakley et al., 2010; Bernhard et al., 2005) and in saline sediments (Swan et al., 2010; Hollister et al., 2010), with changes in the abundance of specific functional groups, such as ammonia-oxidizing (Bernhard et al., 2005) and sulfate-reducing bacteria (Oakley et al., 2010), and overall composition (Hollister et al., 2010; Swan et al., 2010; Bouvier and del Giorgio, 2002), suggesting the important selective role of salinity. However, it is not known how these taxonomic shifts will change the functional gene content involved in biogeochemical processes, with the majority of studies focusing on taxonomic marker genes or specific functional groups.

Metagenomics allows for the elucidation of the biochemical potential of microbial genomes present in a given environmental sample via direct sequencing of community DNA (Tyson et al., 2004; Wooley et al., 2010). Several metagenomic studies (Kunin et al., 2008; Rodriguez-Brito et al., 2010) have focused on specific hypersaline environments, but there has been no assessment of metabolic shifts along salinity gradients. Additionally, the majority of nonmetagenomic studies have investigated either estuarine habitats that do not exceed 50 salinity (Practical Salinity Scale) or extreme hypersaline environments (e.g. solar salterns).

In this context, the Coorong lagoon, in South Australia provides a unique model system of a continuous, natural salinity gradient from estuarine to hypersaline salinities (Lester and Fairweather, 2009; Schapira et al., 2009), which provides an opportunity to investigate shifts in the biogeochemical potential and function of microbial communities.

The Coorong lagoon is one of Australia's most significant wetlands and is listed under the Ramsar convention as a wetland of international significance (Kingsford et al., 2011). The $150 \mathrm{~km}$ long, $2 \mathrm{~km}$ wide system is contained between the last interglacial dune before the ocean and a modern peninsula that has been established from the mid-holocene. The system receives water inputs at one end from the Southern Ocean and the Murray River, Australia's largest freshwater system. These combined inputs result in an estuarine system at the mouth of the lagoon that becomes hypersaline along the gradient due to evaporation. In recent decades, reduced freshwater inputs due to agricultural practices and anthropogenic barriers, coupled with climate driven increases in evaporation and decreases in rainfall, have resulted in increasingly hypersaline conditions within the lagoon (Lester and Fairweather, 2009). This has led to a shift in the biogeochemical status of the system with increased nutrient levels, acidification, and degradation of the overall ecological condition of the wetland (Lester and Fairweather, 2009; Kings- ford et al., 2011). A better knowledge of the response of microbial communities to these conditions is essential from the perspective of both (i) ecosystem management and (ii) as a model to understand the effect of increased salinity levels on microbially mediated biogeochemical cycles. While microbial and viral abundance and activity has been shown to increase along this salinity gradient (Schapira et al., 2009, 2010; Pollet et al., 2010), the identity and metabolic potential of the bacteria that drive particular steps in a biogeochemical cycle have not been characterized in this system.

We conducted a metagenomic survey of the Coorong lagoon as a model for continuous natural salinity and nutrient gradients, and describe the shifts in gene content of sediment microbial metagenomes along the salinity gradient from marine to hypersaline conditions. This provides a model for how environmental gradients can drive shifts in the biogeochemically important metabolic processes involved in salinity tolerance and in taxonomic groups involved in photosynthesis and nitrogen cycling.

\section{Materials and methods}

\subsection{Study sites and sample collection}

Sampling was conducted at four reference stations along the Coorong lagoon, South Australia, in January 2008, during the Austral summer. Salinity varied by 99 across stations, expressed using the Practical Salinity Scale (Lewis, 1980). The sites were named by their salinity and defined by their GPS coordinates, which were as follows: $37\left(-35.551^{\circ} \mathrm{S}\right.$, $\left.138.883^{\circ} \mathrm{E}\right), 109\left(-35.797^{\circ} \mathrm{S}, 139.317^{\circ} \mathrm{E}\right), 132(-35.938 \mathrm{~S}$, $\left.139.488^{\circ} \mathrm{E}\right) \& 136\left(-36.166^{\circ} \mathrm{S}, 139.651^{\circ} \mathrm{E}\right)$. Ammonia concentrations at these sites ranged between $0.21( \pm 0.09)$ and $3.10( \pm 0.84) \mathrm{mgN}^{-1}$, phosphate concentrations ranged between $0.05( \pm 0.01)$ and $0.27( \pm 0.09) \mathrm{mgPl}^{-1}$ (Supplement Fig. S1). Heterotrophic bacteria and virus like particles in porewater, as determined by flow cytometry (Marie et al., 1995; Seymour et al., 2005), increased from $4.8 \times 10^{6}$ $\left( \pm 6.3 \times 10^{5}\right)$ to $1.5 \times 10^{8}\left( \pm 1.4 \times 10^{7}\right)$ bacteria per $\mathrm{mL}$ and $1.5 \times 10^{7}\left( \pm 5.8 \times 10^{6}\right)$ to $4.2 \times 10^{8}\left( \pm 3.1 \times 10^{7}\right)$ viruses per $\mathrm{mL}$ along the salinity gradient (Supplement Fig. S1).

At each site, $10 \mathrm{~g}$ of sediment, submerged in approximately $2 \mathrm{~m}$ deep water was sampled using a sterile corer. This equated to a core containing the upper $10 \mathrm{~cm}$ of sediment. This sampling approach averages out the vertical heterogeneity present in the sample, combining chemical gradients and pooling both oxic sand and black anaerobic mud. In each sample approximately $7 \mathrm{~cm}$ of the core was dark grey and black mud overlaid by approximately $3 \mathrm{~cm}$ of pale sand. Sediment cores on this scale demonstrate strong vertical gradients in Oxygen, Nitrogen, Carbon, and Sulfur (Paerl and Pickney, 1996). As our focus was on regional-scale rather than micro-scale shifts it was necessary to incorporate all of this heterogeneity in our sample to characterize the bulk 
metagenomic potential of the upper surface sediment, in a similar fashion to which water metagenomic studies (e.g. Dinsdale et al., 2008; Rusch et al., 2007) and sediment 16S rDNA studies (e.g. Hollister et al., 2010) combine spatially heterogeneous samples to investigate regional scale shifts. Samples were stored on ice prior to DNA extraction which was performed within $8 \mathrm{~h}$ of collection.

\subsection{DNA extraction and sequencing}

DNA was extracted from $10 \mathrm{~g}$ of homogenized sediment using a bead beating and chemical lysis procedure (Powersoil, MoBio). Four shotgun metagenomic libraries were generated and sequenced using 454 GS-FLX pyrosequencing technology (Roche) at the Australian Genome Research Facility. This sequencing yielded 68888 DNA sequences in the 37 salinity metagenome, 101003 sequences in the 109 salinity metagenome, 114335 sequences in the 132 salinity metagenome and 108257 sequences in the 136 salinity metagenome, with an average read length of $232 \mathrm{bp}$.

\subsection{Bioinformatics and statistical analysis}

Unassembled DNA sequences (environmental sequence tags) from each site were annotated using the MG-RAST pipeline (Meyer et al., 2008). MG-RAST implements the automated BLASTX annotation of DNA sequencing reads to the SEED non redundant database which is a database of genome sequences organized into cellular functions termed subsystems (Overbeek et al., 2005). Within MG-RAST, metabolic assignments were annotated to the SEED subsystems database (Overbeek et al., 2005) and taxonomic identification was determined based on the top BLAST hit to the SEED taxonomy. The SEED is organized in three hierarchical levels for metabolism and six for taxonomy and allows for data to be exported at each level. The heat map function of MG-RAST version 3.0 was used to display the normalized abundance of sequences matching different categories with the Euclidian distance between profiles being displayed as a ward-based clustering dendogram. Taxonomic and metabolic reconstructions generated using MG-RAST version 2.0 with an E-value cutoff of $1 \times 10^{-5}$ and a $50 \mathrm{bp}$ minimum alignment length were imported into the STatistical Analysis of Metagenomic Profiles (STAMP) package to test for statistically significant abundance differences in taxonomic and metabolic groupings (Parks and Beiko, 2010). These were investigated at the second and third level of the MG-RAST metabolic hierarchy and the third level of the MG-RAST taxonomic hierarchy. Fisher's exact test was used to determine the most significantly different categories, with a Storey's FDR multiple test correction applied (Agresti, 1990; Storey and Tibshirani, 2003). Confidence intervals were determined using a Newcombe-Wilson method (Newcombe, 1998). Results were filtered to display only categories with a q-value of $<0.05$. Fisher's exact test uses a hypergeometric distribution of sequences drawn without replacement from a pair of metagenomic samples to generate a statistical significance value in a computationally efficient manner (Parks and Beiko, 2010) and is thus ideal for the pairwise comparison of metagenomes. Fisher's exact test has been routinely applied to observe statistically significant differences between single metagenomic profiles (e.g. Lamendella et al., 2011; McCarthy et al., 2011; Biddle et al., 2011). The Salinity tolerance of identified taxa were determined within the MEGAN software package (Huson et al., 2009) using the NCBI prokaryotic attributes table to display the results of a BLASTX search of our datasets against the NCBI non redundant database using CAMERA (Sun et al., 2011).

\section{Results}

\subsection{Overall shifts in metagenomic profiles}

To investigate the influence of salinity on the composition of the Coorong sediment metagenomes, we compared the abundance profiles of the metabolic potential (Fig. 1a) and the taxonomic identity of genes (Fig. 1b) sampled along the gradient. In both cases the metagenomic profiles demonstrated shifts in structure along the gradient. Metagenomes derived from hypersaline sites showed a higher degree of similarity to each other than to the lower salinity (37) metagenome for both function and taxonomic identity. The signature for metabolic potential was more conserved between samples than that for the phylogenetic identity of genes.

\subsection{Shifts in functional potential along the salinity gradient}

We further investigated shifts in the functional gene content of microbial communities along the salinity gradient using STAMP (Parks and Beiko, 2010) to determine which finer level metabolic processes were statistically over-represented in the hypersaline metagenomes relative to the marine (37) metagenome (Fig. 2). This was investigated at the second level of the MG-RAST metabolic hierarchy.

Genes responsible for the synthesis of cell membrane bound $\mathrm{ABC}$ transporter proteins, predominantly composed of branched chain amino acid and oligopeptide transporters (Fig. 3a), were over-represented in the hypersaline metagenomes (Fig. 2), as were ATP synthase enzymes (Fig. 2a and c) and pathways responsible for the cellular response to osmotic stress. Osmotic stress genes were primarily involved in the synthesis and transport of the osmoprotectants choline, betaine, ectoine and periplasmic glucans (Fig. 3b). DNA metabolism genes and the genes responsible for the metabolism of di- and oligosaccharide sugars were also significantly more abundant in the hypersaline metagenomes than in the 37 salinity metagenome. 
A)

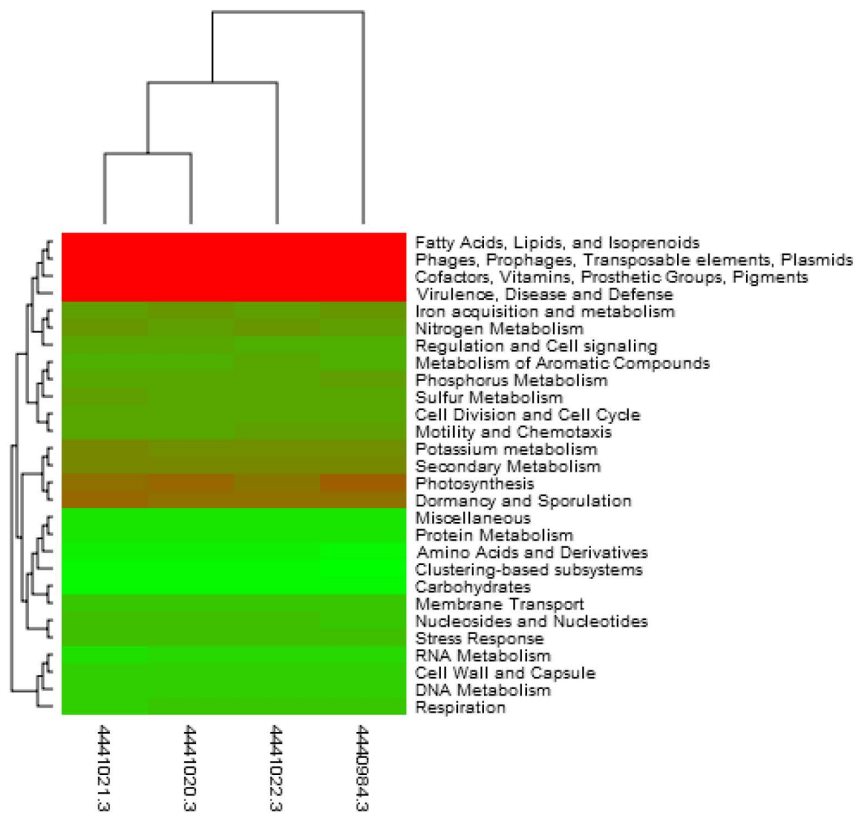

B)

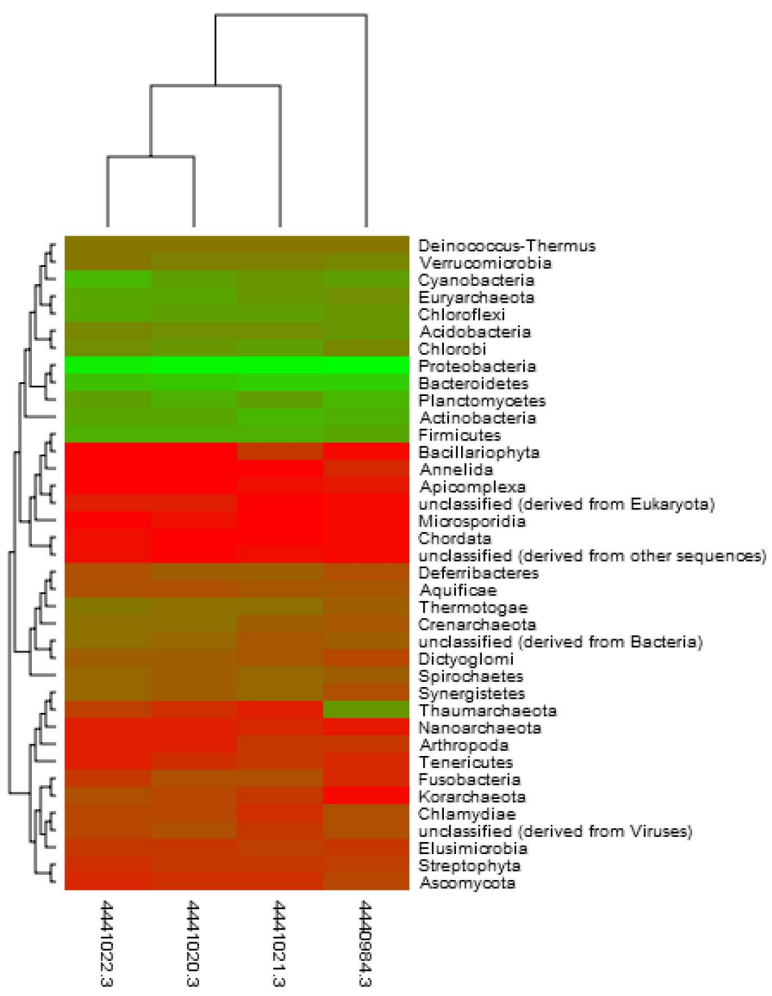

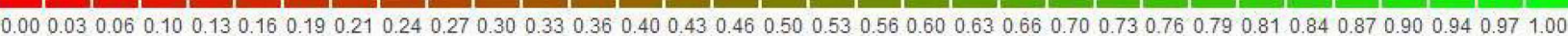

Fig. 1. Disimilarity between metagenomic profiles. (A) Functional potential $($ B) Taxonomic composition. $4440984.3=37,4441020.3=$ $109,4441021.3=132,4441022.3=136$. Colour gradient represents proportion of sequences. 

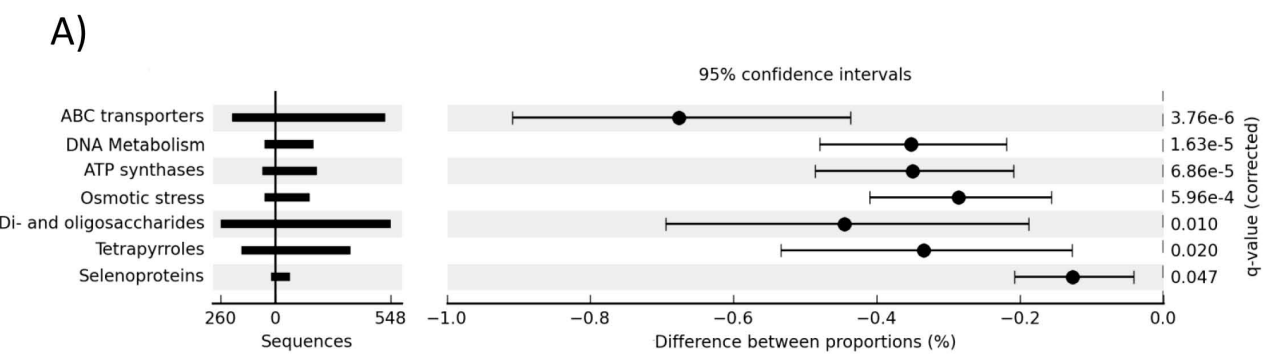

\section{B)}
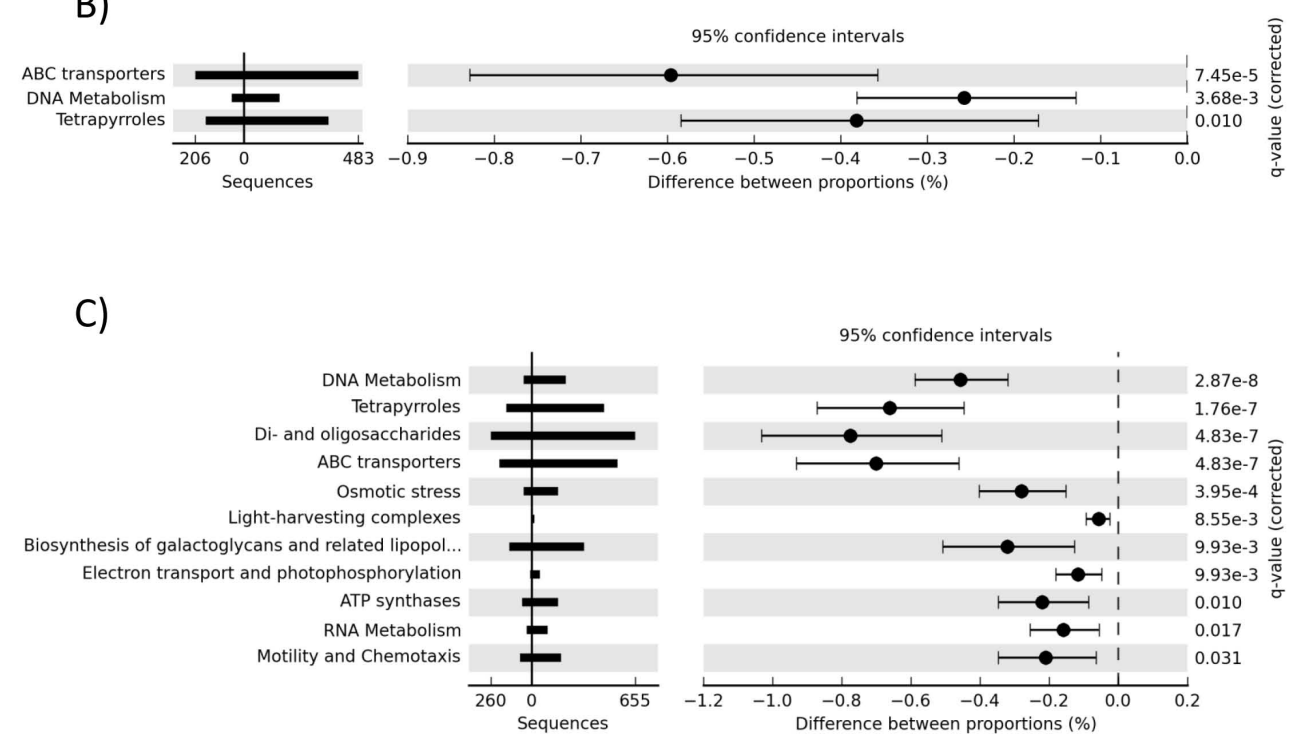

Fig. 2. Metabolic processes over-represented in hypersaline metagenomes relative to the 37 metagenome. (A) 109 (B) 132 (C) 136 . Corrected P-values were calculated using Storey's FDR approach.

Sequences related to photosynthesis and pigment synthesis were over-represented in all hypersaline metagenomes relative to the 37 metagenome (Fig. 2). Specifically, the abundance of sequences matching tetrapyrrole synthesis (chlorophyll) and photosynthetic electron transport and photophosphorylation pathways were significantly higher in the hypersaline metagenomes than in the 37 metagenome.

\subsection{Shifts in taxonomic identity of genes along the salinity gradient}

We further investigated the taxonomic identity of genes along the salinity gradient using STAMP (Parks and Beiko, 2010) to determine which finer level taxonomic groups were statistically different in abundance between the 37 metagenome and the hypersaline metagenomes (Fig. 4, Supplement Fig. S2). The cyanobacterial classes Nostocales, Oscillatoriales and Chroococcales were found to be overrepresented in the most hypersaline metagenome (136) relative to the lower salinity sample (Fig. 4), as was the photoheterotrophic bacterial class Chloroflexi, which contains the green non-sulfur bacteria.
Several archaeal taxa were over-represented in the 109 , 132 and 136 metagenomes relative to the 37 sample. Of these, the class Methanomicrobia was the most overrepresented in all cases. The halophilic class Halobacteria were over-represented in the 136 and 109 metagenomes showing the highest increase in proportion in the most hypersaline metagenome (136) (Fig. 4; Supplement Fig. S2).

We also observed shifts in the structure of the Proteobacteria. The class Delta/Epsilon-Proteobacteria were overrepresented in hypersaline metagenomes, while the relative abundance of Gammaproteobacteria, Betaproteobactera and Alphaproteobacteria were significantly higher in the lower salinity metagenome. The classes Bacteroidetes and Plactomycetacia were also strongly over-represented in the lower salinity metagenome.

To investigate how these shifts in taxon abundance were reflected in the salinity tolerance of members of the microbial community, we used MEGAN (Huson et al., 2009) to summarize taxonomic assignments of sequencing reads in NCBI's microbial attributes table. We found that the proportion of reads matching moderate halophiles and extreme 


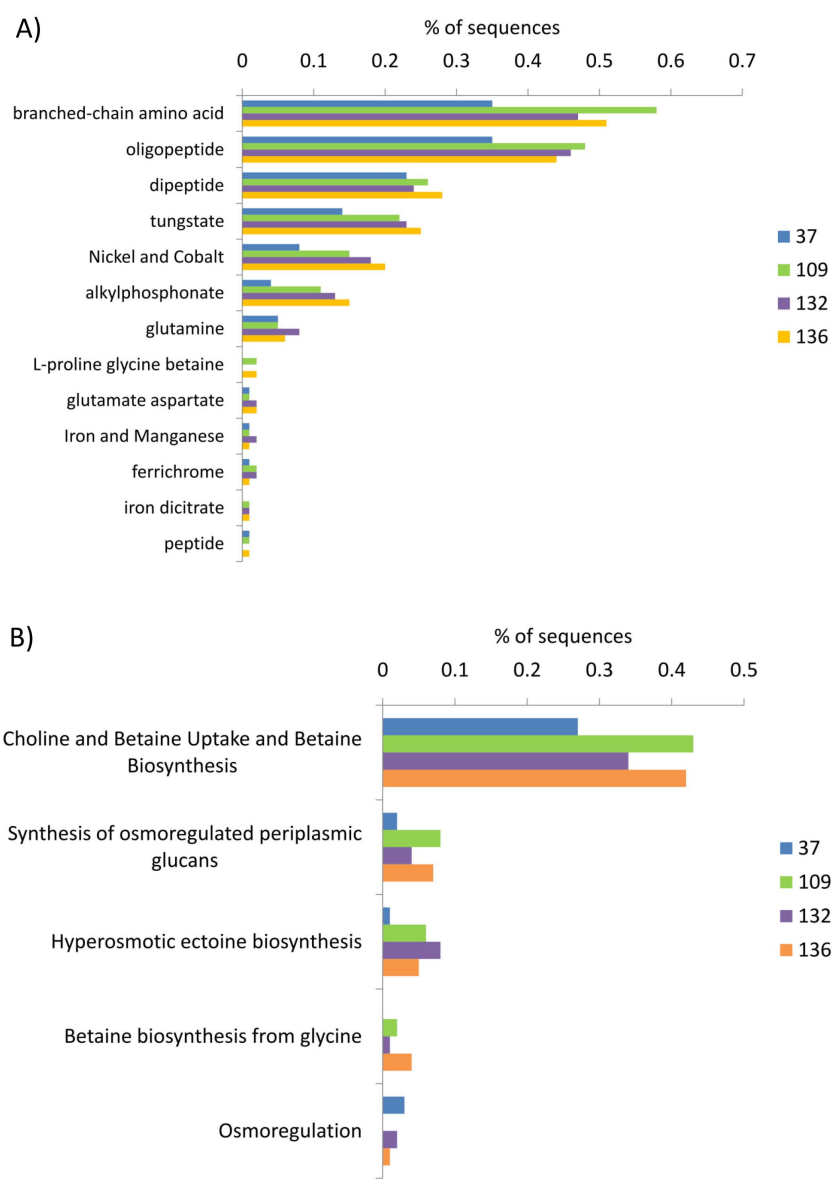

Fig. 3. Breakdown of subsystem contribution to (A) ABC transporter and (B) osmotic stress categories. Subsystems are the third level of organization within the MG-RAST hierarchy.

halophiles increased by $5 \%$ and $6 \%$ respectively, and that the total number of moderate and extreme halophilic taxa increased from 15 to 32 in the 136 salinity metagenome relative to the 37 metagenome (Fig. 5). Overall the majority of identifiable taxa in both of these communities were mesophilic and moderately halophilic.

\section{Discussion}

Our results comprise the first metagenomic survey of a model continuous natural salinity gradient and describe the shifts in gene content of sediment microbial metagenomes along the gradient from marine to hypersaline salinities. Overall shifts in the genetic composition of the metagenomes highlighted the substantial influence of salinity on the metabolic potential of microbial communities, which in turn has biogeochemical consequences. Taxonomic shifts may also reflect variation in other variables such as nutrient concentration and the relative amount of oxic and anoxic sediment present in each core, however the nature of metabolic shifts along the gradient in- dicate that salinity is a dominant factor, as does the increased representation of halophiles along the gradient.

The most significant differences along the gradient can be categorized into two biogeochemically important categories: osmotic stress tolerance, via acquisition of compatible solutes, and photosynthesis. Our data allows us to form several new hypotheses relating to how microbial communities may respond to increasing salinity levels in the environment, and influence the biogeochemistry of salinity gradient habitats.

\subsection{Salinity tolerance via compatible solute acquisition and its influence on carbon and nutrient cycling}

Many of the metabolic pathways over-represented in the hypersaline metagenomes (Fig. 2) are potentially involved in cellular halotolerance. Microorganisms can overcome the osmotic stress caused by increased salt concentration by two mechanisms: the accumulation of $\mathrm{KCl}$, which requires heavy modification of the enzyme content of the cell, or by accumulating organic compatible solutes which requires less proteomic modification and allows adaptation to a broad salinity range (Oren, 2008). It is this "organic solutes in" strategy that seems most prevalent in our data. Osmotic stress functional categories were over-represented in hypersaline metagenomes and these were largely composed of pathways responsible for choline, betaine and ectoine transport and synthesis, and the acquisition of periplasmic glucans. These solutes are common osmoprotectants in halotolerant and halophilic microorganisms. In particular, ectoine and betaine are important osmolytes in a wide range of taxonomic groups (Oren, 2008; Roberts, 2005) and betaine is an important characteristic of halotolerant Cyanobacteria and other phototrophic bacteria (Welsh, 2000). Choline is a precursor for betaine synthesis and its concentration has been shown to be salt dependant in halophilic bacteria (Roberts, 2005; Canovas et al., 1998).

Consistent with the osmoregulated accumulation of solutes, di- and oligosaccharide functional categories were over-represented in both hypersaline metagenomes (Fig. 2) and the biosynthesis of other sugars (galactoglycans/lipopolysaccharide) was also enriched in the most hypersaline metagenome. Many sugars act as osmoprotectants (Oren, 2008; Roberts, 2005) for example trehalose is a common compatible solute in a variety of halotolerant and halophilic microorganisms, and sucrose in halotolerant cyanobacteria and proteobacteria (Roberts, 2005). The presence of elevated sugar biosynthesis has the biogeochemical implications that microbially mediated cycling can occur at higher salinities and that there will be more energy available in the form of sugars to stimulate the metabolism of biogeochemically active heterotrophic bacteria.

Genes responsible for the synthesis of cell membrane bound ATP binding cassette (ABC) transporter proteins were over-represented in both hypersaline metagenomes and also potentially play a role in salinity tolerance. In our data, these 

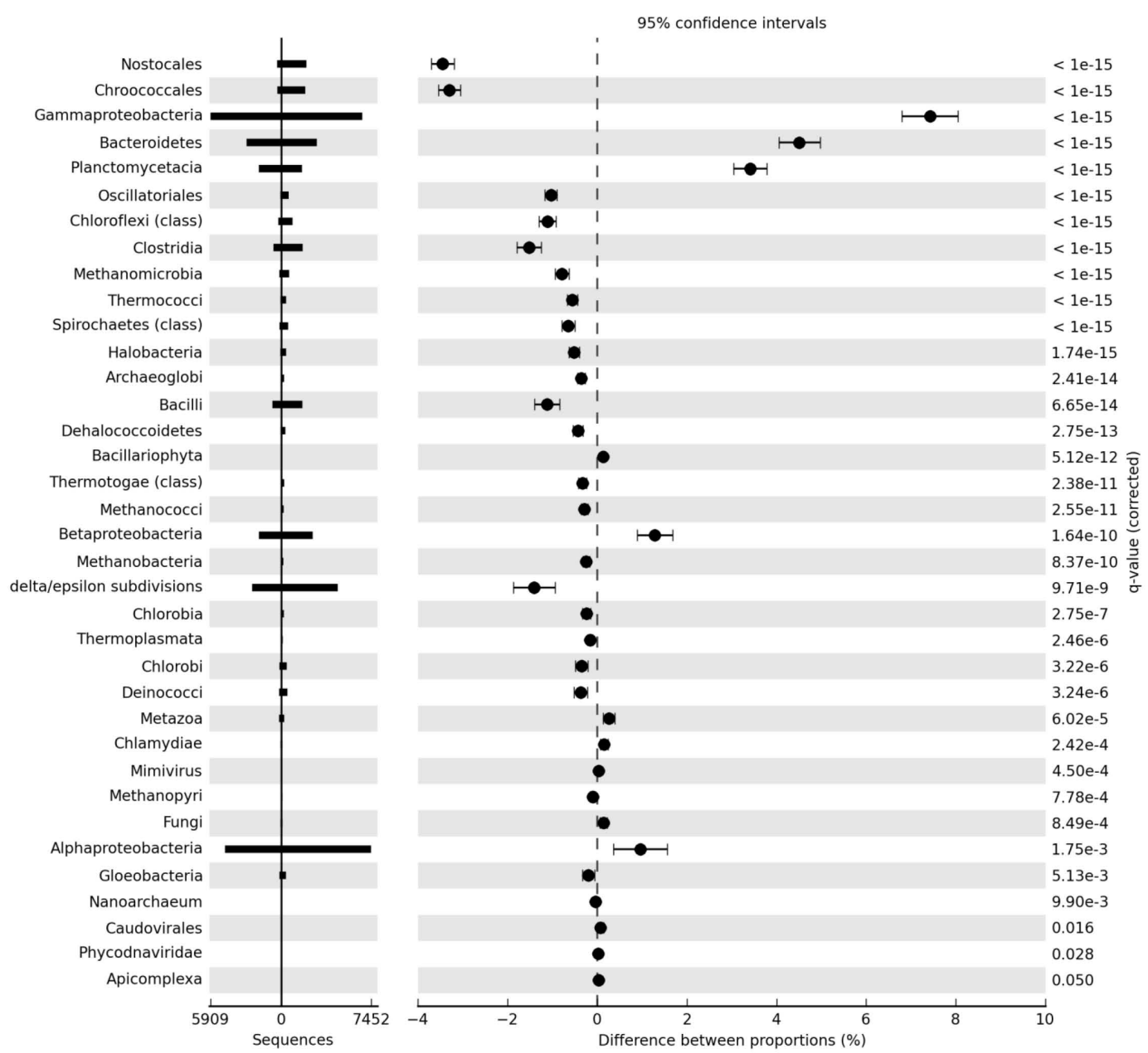

Fig. 4. Taxa enriched or depleted in the 37 and 136 metagenomes. Corrected P-values were calculated using Storey's FDR approach. Taxa enriched in the marine (37) metagenomes have positive differences between proportions.

enzymes were largely dominated by those involved in the transport of branched chain amino acids. Amino acids are common compatible solutes (Oren, 2008) and a branched chain amino acid ABC-transporter has been transcriptionally up-regulated during salt adaptation in the sediment bacteria Desulfovibrio vulgaris along with other $\mathrm{ABC}$ transporters responsible for betaine transport (He et al., 2010). The overrepresentation of sequences for ATP synthase enzymes is also potentially explained by halotolerance as these membrane bound pumps are up regulated in salt stressed yeast (Yale and Bohnert, 2001) and a novel form of this enzyme plays a role in salinity tolerance in halotolerant Cyanobacteria (Soontharapirakkul et al., 2011).

In addition to providing survivability to the increasing biomass present in the hypersaline samples, which is reflected in the increase in halotolerant and halophilic taxa along the gradient, the increased synthesis and uptake of compatible solutes also has direct consequences for the nutrient cycling and greenhouse gas emissions of the sedi- ment. The extent to which compatible solute metabolism influences primary production and provides key substrates for heterotrophic nutrition is still to be determined (Oren, 2009), but the release of osmoprotectants via diffusion, lysis and grazing provides a significant source of carbon, nitrogen and sulfur to heterotrophic microorganisms (Welsh, 2000; Howard et al. 2006). This process appears to be particularly important in hypersaline sediments and mats where the utilization of high concentration glycine-betaine, trehalose and sucrose represent a significant carbon source for microorganisms and where glycine betaine can represent up to $20 \%$ of the total nitrogen of the surface layers (Welsh, 2000; King, 1988). The potentially increased catabolism of betaine is particularly significant in hypersaline sediment where anaerobic degradation of this compound may result in methane as an end product (Welsh, 2000). Members of the class Methanosarcinales, which is over-represented in the most hypersaline metagenome, contain the order Methanosarcinales which metabolize methylated amines, formed from the 


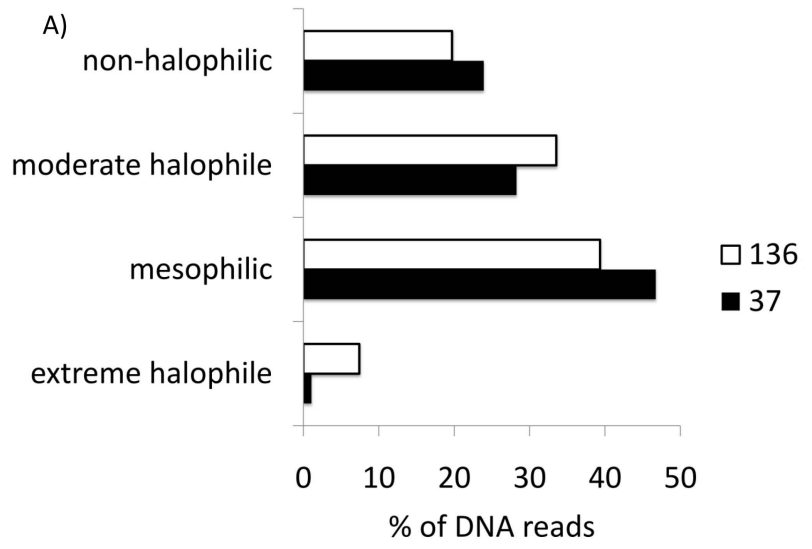

B)

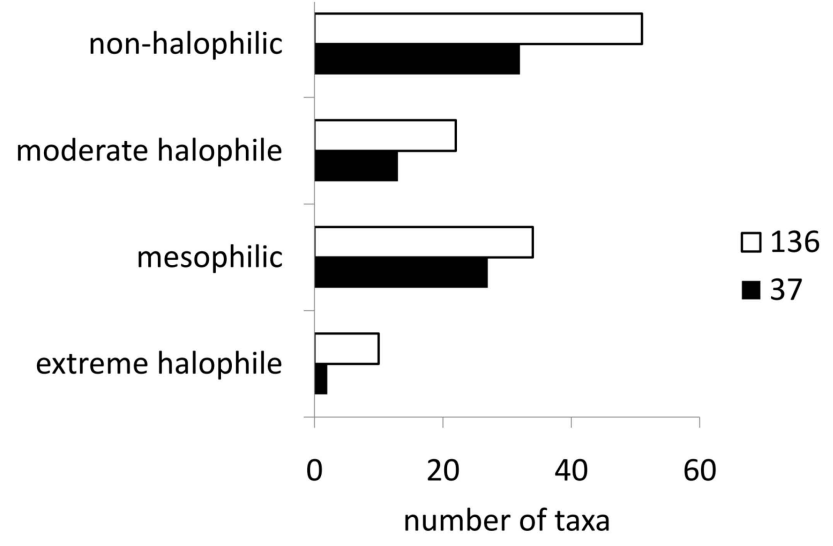

Fig. 5. Representation of halophilic taxa in the 37 and 136 metagenomes. (A) \% DNA reads matching taxa with a defined salinity tolerance (B) number of taxa with a defined salinity tolerance.

breakdown of the osmoprotectant glycine betaine (Kendall and Boone, 2006), potentially influencing the rates of methane flux in the sediment. Additionally, the climate regulating gas dimethylsulfide (DMS) precursor dimethylsulfoniopropionate (DMSP) is a structural analogue to betaine and shares a cellular transport system (Welsh, 2000), thus the increased abundance of betaine transport potential with salinity could also result in an increase in the accumulation of this solute which is central to global scale climate and sulfur cycles. Thus, the observation that metabolisms related to compatible solute metabolism are over-represented in hypersaline metagenomes directly links the halotolerant metabolic potential of the community to global scale nutrient cycles and climate processes, and suggest that with increasing salinity, this influence will become further exaggerated.

The presence of sequences matching the Halobacteriacea further indicates an adapted halophilic community as these Archaea tend to be found at the highest salinities and generally use a "high-salt in" strategy (Oren, 2008), which suggests that this mode of salt adaptation is also present in our samples. Sequences and isolates matching the Halobacteriales have been observed in the hypersaline microbial mats of Shark Bay, Australia (Goh et al., 2006; Burns et al., 2004; Allen et al., 2008) indicating that they are an important constituent of benthic microbial communities that exist at more moderate hypersaline conditions as well as at the extremes of salt saturation.

\subsection{Photosynthesis}

The over-representation of sequences matching tetrapyrrole synthesis (chlorophyll) and photosynthetic electron transport and photophosphorylation pathways in the hypersaline metagenomes is consistent with the overrepresentation of Cyanobacteria in the most saline metagenome. Cyanobacteria are abundant in hypersaline systems (Javor, 1989; Oren, 2002) particularly in the form of benthic microbial mats which drive primary productivity in hypersaline environments between 100 and $200 \mathrm{gl}^{-1}$ salinity (Oren, 2009). The Cyanobacteria over-represented in our most hypersaline metagenome represent filamentous Cyanobacteria. Many taxa comprising mats are filamentous (Oren, 2002, 2009), however the sediment we sampled in this study did not show the laminated structure characteristic of cyanobacterial mats, but was sandy sediment dominated by non photosynthetic taxa. Our data indicate that increasing salinity could potentially increase the presence of filamentous Cyanobacteria without precipitating the transformation of porous sediment into laminated mats. Mats are associated with photosynthesis and nitrogen cycling but our results indicate that these processes occur significantly in sediments without the visual presence of stratified mat communities. The occurrence of abundant Nostocales sequences in our metagenomes is unexpected as while Nostocales have also been observed in saline Antarctic lakes (Jungblut and Neilan, 2010) and in the hypersaline stromatolites of Shark Bay, Australia (Burns et al., 2004), there are indeed no reports that we could find of high abundance Nostocales in samples as hypersaline as ours. Our data could either describe a novel group of halophilic heteroscystous Nostocales, which would require further microscopic analysis and detailed molecular taxonomic classification to confirm, or potentially our Nostocales sequences are derived from other filamentous cyanobacterial taxa which are closely related to Nostocales, for which there are no examples in the SEED database used for taxonomic classification.

Salinity often co-varies with other parameters such as nutrient concentration and microbial/viral abundance (Schapira et al., 2009) thus other gradients in the system can be expected to influence the abundance of Cyanobacteria and determine their morphology, such as the increase in ammonia and phosphate concentration observed in our data (Supplement Fig. S1). Larger cells with small surface to volume ratios, such as colonial and filamentous cyanobacteria, preferentially grow at higher nutrient concentrations and find a niche when protozoan grazing is high (Cotner and Biddanda, 
2002; Pernthaler et al., 2004). Reduced grazing due to high salinity also facilitates the development of stratified mats (Oren, 2009) however grazing is still prevalent in the hypersaline Coorong (Newton et al., 2012) potentially limiting the formation of these structures, but favoring filamentous morphologies.

The increase of photosynthetic metabolisms and taxa in the most hypersaline metagenome (136 PSU) has implications for the exchange of nutrients and $\mathrm{CO}_{2}$ between the benthic and pelagic systems within the lagoon. Photosynthetic microbial mats and similar environments release dissolved organic carbon and oxygen to the environment and act as a sink for $\mathrm{CO}_{2}$ (Ford, 2007). Photosynthetic benthic surfaces also provide energy for nitrogen fixation in underlying sediments as well as capturing phosphorous and sulfur from the overlying water (Ford, 2007). Another interesting trend in our data is the higher level of ammonium in hypersaline sediments compared to the lower salinity (37) sediment (Supplement Fig. S1). This is potentially related to the potential negative influence of high salt concentrations on nitrifying bacteria, such as the genera Nitrosomonas and Nitrosococcus, which are both present in our data further suggesting that salinity may be influencing other taxonomic groups relevant to the nitrogen cycle.

Whilst the extent of these environments in the Coorong remain unknown and the overall influence of salinity on production rates and nutrient flux remains undetermined (Ford, 2007), our data indicate that this habitat could become more common with further increases in salinity, which have been predicted to occur in environments such as the Coorong due to climate change (Hughes, 2003), altering the primary productivity and nutrient levels of lagoons and potentially altering mineral precipitation via changes in DOC concentration (Javor, 1989).

\section{Concluding remarks}

Our study comprises the first metagenomic characterization of a model hypersaline, continuous and natural salinity gradient and describes the shifts in gene content of sediment microbial metagenomes in the system. Shifts in the biochemical potential and identity of the microorganisms controlling the potential can be summarized as an increase in halotolerant and benthic photosynthetic forms with salinity. This data provides the first direct observation of an increase in genes responsible for the acquisition of compatible solutes in a natural hypersaline environment as opposed to in culture. The biogeochemical implications of an increase in compatible solute acquisition and increased benthic photosynthesis potentially represent important drivers of the ecosystem biogeochemistry. Given the ecological and biogeochemical importance of salinity gradients and increased pressure on these systems from climate change and its associated effects, understanding microbial adaptation to increasing salinity at the community level is crucial to predicting how the biogeochemistry of aquatic habitats will change over space and time.

\section{Supplementary material related to this article is available online at: http://www.biogeosciences.net/9/815/2012/ bg-9-815-2012-supplement.pdf.}

Acknowledgements. This work was supported by the Australian Research Council. We thank Aharon Oren and an anonymous reviewer for their comments on this manuscript during open discussion.

Edited by: G. Herndl

\section{References}

Agresti, A.: Categorical data analysis, Wiley series in probability and mathematical statistics Applied probability and statistics, Wiley, New York, xv, 558 pp., 1990.

Allen, M. A., Goh, F., Leuko, S., Echigo, A., Mizuki, T., Usami, R., Kamekura, M., Neilan, B. A., and Burns, B. P.: Haloferax elongans sp. nov. and Haloferax mucosum sp. nov., isolated from microbial mats from Hamelin Pool, Shark Bay, Australia, International Journal of Systematic and Evolutionary Microbiology, 58, 798-802, 2008.

Benlloch, S., Lopez-Lopez, A., Casamayor, E. O., Ovreas, L., Goddard, V., Daae, F. L., Smerdon, G., Massana, R., Joint, I., Thingstad, F., Pedros-Alio, C., and Rodriguez-Valera, F.: Prokaryotic genetic diversity throughout the salinity gradient of a coastal solar saltern, Environ. Microbiol., 4, 349-360, 2002.

Bernhard, A. E., Donn, T., Giblin, A. E., and Stahl, D. A.: Loss of diversity of ammonia-oxidizing bacteria correlates with increasing salinity in an estuary system, Environ. Microbiol., 7, 12891297, doi:10.1111/j.1462-2920.2005.00808.x, 2005.

Biddle, J. F., White, J. R., Teske, A. P., and House, C. H.: Metagenomics of the subsurface Brazos-Trinity Basin (IODP site 1320): comparison with other sediment and pyrosequenced metagenomes, ISME J., 5, 1038-1047, 2011.

Bouvier, T. C. and del Giorgio, P. A.: Compositional changes in free-living bacterial communities along a salinity gradient in two temperate estuaries, Limnol. Oceanogr., 47, 453-470, 2002.

Burns, B. P., Goh, F., Allen, M., and Neilan, B. A.: Microbial diversity of extant stromatolites in the hypersaline marine environment of Shark Bay, Australia, Environmental Microbiology, 6, 1096-1101, 2004.

Canovas, D., Vargas, C., Csonka, L. N., Ventosa, A., and Nieto, J. J.: Synthesis of Glycine Betaine from Exogenous Choline in the Moderately Halophilic Bacterium Halomonas elongata, Appl. Environ. Microbiol., 64, 4095-4097, 1998.

Cotner, J. B. and Biddanda, B. A.: Small Players, Large Role: Microbial Influence on Biogeochemical Processes in Pelagic Aquatic Ecosystems, Ecosystems, 5, 105-121, doi:10.1007/s10021-001-0059-3, 2002.

Dinsdale, E. A., Pantos, O., Smriga, S., Edwards, R. A., Angly, F., Wegley, L., Hatay, M., Hall, D., Brown, E., Haynes, M., Krause, 
L., Sala, E., Sandin, S. A., Thurber, R. V., Willis, B. L., Azam, F., Knowlton, N., and Rohwer, F.: Microbial Ecology of Four Coral Atolls in the Northern Line Islands, PLoS ONE, 3, E1584, doi:10.1371/journal.pone.0001584, 2008.

Estrada, M., Henriksen, P., Gasol, J. M., Casamayor, E. O., and Pedros-Alio, C.: Diversity of planktonic photo auto trophic microorganisms along a salinity gradient as depicted by microscopy, flow cytometry, pigment analysis and DNA-based methods, FEMS Microbiol. Ecol., 49, 281-293, doi:10.1016/j.femsec.2004.04.002, 2004.

Falkowski, P. G., Fenchel, T., and Delong, E. F.: The microbial engines that drive Earth's biogeochemical cycles, Science, 320, 1034-1039, doi:10.1126/science.1153213, 2008.

Ford, P. W.: Biogeochemistry of the Coorong. Review and identification of future research requirements., Water for a Healthy Country Flagship, CSIRO, 33 pp., 2007.

Fuhrman, J. A.: Microbial community structure and its functional implications, Nature, 459, 193-199, doi:10.1038/Nature08058, 2009.

Goh, F., Leuko, S., Allen, M. A., Bowman, J. P., Kamekura, M., Neilan, B. A., and Burns, B. P.: Halococcus hamelinensis sp. nov., a novel halophilic archaeon isolated from stromatolites in Shark Bay, Australia, International Journal of Systematic and Evolutionary Microbiology, 56, 1323-1329, doi:10.1099/ijs.0.64180-0, 2006.

He, Z., Zhou, A., Baidoo, E., He, Q., Joachimiak, M. P., Benke, P., Phan, R., Mukhopadhyay, A., Hemme, C. L., Huang, K., Alm, E. J., Fields, M. W., Wall, J., Stahl, D., Hazen, T. C., Keasling, J. D., Arkin, A. P., and Zhou, J.: Global Transcriptional, Physiological, and Metabolite Analyses of the Responses of Desulfovibrio vulgaris Hildenborough to Salt Adaptation, Appl. Environ. Microbiol., 76, 1574-1586, doi:10.1128/aem.02141-09, 2010.

Hollister, E. B., Engledow, A. S., Hammett, A. J. M., Provin, T. L., Wilkinson, H. H., and Gentry, T. J.: Shifts in microbial community structure along an ecological gradient of hypersaline soils and sediments, ISME J., 4, 829-838, doi:10.1038/ismej.2010.3, 2010.

Howard, E. C., Henriksen, J. R., Buchan, A., Reisch, C. R., Bürgmann, H., Welsh, R., Ye, W., González, J. M., Mace, K., Joye, S. B., Kiene, R. P., Whitman, W. B., and Moran, M. A.: Bacterial taxa that limit sulfur flux from the ocean, Science, 314, 649-652, doi:10.1126/science.1130657, 2006.

Hughes, L.: Climate change and australia: Trends, projections and impacts, Austral Ecology, 28, 423-443, 2003.

Huson, D. H., Richter, D. C., Mitra, S., Auch, A. F., and Schuster, S. C.: Methods for comparative metagenomics, BMC Bioinformatics, 10 Suppl 1, S12, 1471-2105-10-S1-S12 [pii], doi:10.1186/1471-2105-10-S1-S12, 2009.

Javor, B.: Hypersaline environments: microbiology and biogeochemistry, Brock/Springer series in contemporary bioscience, Springer-Verlag, Berlin, New York, viii, 328 pp., 1989.

Jungblut, A. D. and Neilan, B. A.: Cyanobacterial Mats of the Meltwater Ponds on the McMurdo Ice Shelf (Antarctica) Microbial Mats, in: Cellular Origin, Life in Extreme Habitats and Astrobiology, edited by: Seckbach, J. and Oren, A., Springer Netherlands, 499-514, 2010.

Kendall, M. and Boone, D.: The Order Methanosarcinales, in: The Prokaryotes, edited by: Dworkin, M., Falkow, S., Rosenberg, E., Schleifer, K.-H., and Stackebrandt, E., Springer New York, 244
256, 2006.

King, G. M.: Methanogenesis from Methylated Amines in a Hypersaline Algal Mat, Appl. Environ. Microbiol., 54, 130-136, 1988.

Kingsford, R. T., Walker, K. F., Lester, R. E., Young, W. J., Fairweather, P. G., Sammut, J., and Geddes, M. C.: A Ramsar wetland in crisis - the Coorong, Lower Lakes and Murray Mouth, Australia, Mar. Freshwater Res., 62, 255-265, doi:10.1071/mf09315, 2011.

Kunin, V., Raes, J., Harris, J. K., Spear, J. R., Walker, J. J., Ivanova, N., von Mering, C., Bebout, B. M., Pace, N. R., Bork, P., and Hugenholtz, P.: Millimeter-scale genetic gradients and community-level molecular convergence in a hypersaline microbial mat, Mol. Syst. Biol., 4, 198, doi:10.1038/msb.2008.35, 2008.

Lamendella, R., Santo Domingo, J., Ghosh, S., Martinson, J., and Oerther, D.: Comparative fecal metagenomics unveils unique functional capacity of the swine gut, BMC Microbiology, 11, 103, doi:10.1186/1471-2180-11-103, 2011.

Lester, R. E. and Fairweather, P. G.: Modelling future conditions in the degraded semi-arid estuary of Australia's largest river using ecosystem states, Estuar. Coast Shelf S., 85, 1-11, doi:10.1016/j.ecss.2009.04.018, 2009.

Lewis, E.: The practical salinity scale 1978 and its antecedents, Oceanic Engineering, IEEE Journal of, 5, 3-8, 1980.

Lozupone, C. A. and Knight, R.: Global patterns in bacterial diversity, P. Natl. Acad. Sci. USA, 104, 11436-11440, doi:10.1073/pnas.0611525104, 2007.

McCarthy, C. B., Diambra, L. A., and Rivera Pomar, R. V.: Metagenomic Analysis of Taxa Associated with Lutzomyia longipalpis, Vector of Visceral Leishmaniasis, Using an Unbiased HighThroughput Approach, PLoS Negl. Trop. Diseases, 5, e1304, 2011.

Meyer, F., Paarmann, D., D'Souza, M., Olson, R., Glass, E. M., Kubal, M., Paczian, T., Rodriguez, A., Stevens, R., Wilke, A., Wilkening, J., and Edwards, R. A.: The metagenomics RAST server - a public resource for the automatic phylogenetic and functional analysis of metagenomes, BMC Bioinformatics, 9, 386, doi:10.1186/1471-2105-9-386, 2008.

Marie, D., Brussaard, C. P. D., Thyrhaug, R., Bratbak, G., and Vaulot, D.: Enumeration of marine viruses in culture and natural samples by flow cytometry, Appl. Environ. Microb., 65, 45-52, 1999.

Newcombe, R. G.: Interval estimation for the difference between independent proportions: Comparison of eleven methods, Statistics in Medicine, 17, 873-890, 1998.

Oakley, B. B., Carbonero, F., van der Gast, C. J., Hawkins, R. J., and Purdy, K. J.: Evolutionary divergence and biogeography of sympatric niche-differentiated bacterial populations, ISME J., 4, 488-497, available at: http://www.nature.com/ismej/journal/v4/ n4/suppinfo/ismej2009146s1.html, 2010.

Oren, A.: Salts and Brines, in: The Ecology of Cyanobacteria, edited by: Whitton, B. and Potts, M., Springer Netherlands, 281306, 2000.

Oren, A.: Microbial life at high salt concentrations: phylogenetic and metabolic diversity, Saline Systems, 4, 2, doi:10.1186/17461448-4-2, 2008.

Oren, A.: Saltern evaporation ponds as model systems for the study of primary production processes under hypersaline conditions, Aquat. Microb. Ecol., 56, 193-204, doi:10.3354/ame01297, 
2009.

Overbeek, R., Begley, T., Butler, R. M., Choudhuri, J. V., Chuang, H. Y., Cohoon, M., de Crecy-Lagard, V., Diaz, N., Disz, T., Edwards, R., Fonstein, M., Frank, E. D., Gerdes, S., Glass, E. M., Goesmann, A., Hanson, A., Iwata-Reuyl, D., Jensen, R., Jamshidi, N., Krause, L., Kubal, M., Larsen, N., Linke, B., McHardy, A. C., Meyer, F., Neuweger, H., Olsen, G., Olson, R., Osterman, A., Portnoy, V., Pusch, G. D., Rodionov, D. A., Ruckert, C., Steiner, J., Stevens, R., Thiele, I., Vassieva, O., Ye, Y., Zagnitko, O., and Vonstein, V.: The subsystems approach to genome annotation and its use in the project to annotate 1000 genomes, Nucleic Acids Res., 33, 5691-5702, doi:10.1093/Nar/Gki866, 2005.

Parks, D. H. and Beiko, R. G.: Identifying biologically relevant differences between metagenomic communities, Bioinformatics, 26, 715-721, doi:10.1093/bioinformatics/btq041, 2010.

Paerl, H. W. and Pinckney, J. L.: A mini-review of microbial consortia: Their roles in aquatic production and biogeochemical cycling, Microbial Ecol., 31, 225-247, 1996.

Pedrós-Alió, C., Calderón-Paz, J. I., MacLean, M. H., Medina, G., Marrasé, C., Gasol, J. M., and Guixa-Boixereu, N.: The microbial food web along salinity gradients, FEMS Microbiol. Ecol., 32, 143-155, doi:10.1111/j.1574-6941.2000.tb00708.x, 2000.

Pernthaler, J., Zollner, E., Warnecke, F., and Jurgens, K.: Bloom of Filamentous Bacteria in a Mesotrophic Lake: Identity and Potential Controlling Mechanism, Appl. Environ. Microbiol., 70, 6272-6281, doi:10.1128/aem.70.10.6272-6281.2004, 2004.

Pollet, T., Schapira, M., Buscot, M. J., Leterme, S. C., Mitchell, J. G., and Seuront, L.: Prokaryotic aminopeptidase activity along a continuous salinity gradient in a hypersaline coastal lagoon (the Coorong, South Australia), Saline Systems, 6, doi:10.1186/1746-1448-6-5, 2010.

Roberts, M. F.: Organic compatible solutes of halotolerant and halophilic microorganisms, Saline Systems, 1, doi:10.1186/1746-1448-1-5, 2005.

Rodriguez-Brito, B., Li, L., Wegley, L., Furlan, M., Angly, F., Breitbart, M., Buchanan, J., Desnues, C., Dinsdale, E., Edwards, R., Felts, B., Haynes, M., Liu, H., Lipson, D., Mahaffy, J., Martin-Cuadrado, A. B., Mira, A., Nulton, J., Pasic, L., Rayhawk, S., Rodriguez-Mueller, J., Rodriguez-Valera, F., Salamon, P., Srinagesh, S., Thingstad, T. F., Tran, T., Thurber, R. V., Willner, D., Youle, M., and Rohwer, F.: Viral and microbial community dynamics in four aquatic environments, ISME J., 4, 739-751, available at: http://www.nature.com/ismej/journal/v4/ n6/suppinfo/ismej20101s1.html, 2010.

Rusch, D. B., Halpern, A. L., Sutton, G., Heidelberg, K. B., Williamson, S., Yooseph, S., Wu, D., Eisen, J. A., Hoffman, J. M., Remington, K., Beeson, K., Tran, B., Smith, H., BadenTillson, H., Stewart, C., Thorpe, J., Freeman, J., AndrewsPfannkoch, C., Venter, J. E., Li, K., Kravitz, S., Heidelberg, J. F., Utterback, T., Rogers, Y.-H., Falcón, L. I., Souza, V., BonillaRosso, G., Eguiarte, L. E., Karl, D. M., Sathyendranath, S., Platt, T., Bermingham, E., Gallardo, V., Tamayo-Castillo, G., Ferrari, M. R., Strausberg, R. L., Nealson, K., Friedman, R., Frazier, M., and Venter, J. C.: The Sorcerer II Global Ocean Sampling Expedition: Northwest Atlantic through Eastern Tropical Pacific, PLoS Biol., 5, 0398-0431, 2007.
Scavia, D., Field, J., Boesch, D., Buddemeier, R., Burkett, V., Cayan, D., Fogarty, M., Harwell, M., Howarth, R., Mason, C., Reed, D., Royer, T., Sallenger, A., and Titus, J.: Climate change impacts on U.S. Coastal and Marine Ecosystems, Estuaries and Coasts, 25, 149-164, doi:10.1007/bf02691304, 2002.

Schallenberg, M., Hall, C. J., and Burns, C. W.: Consequences of climate-induced salinity increases on zooplankton abundance and diversity in coastal lakes, Mar. Ecol.-Prog. Ser., 251, 181189, doi:10.3354/meps251181, 2003.

Schapira, M., Buscot, M. J., Leterme, S. C., Pollet, T., Chapperon, C., and Seuront, L.: Distribution of heterotrophic bacteria and virus-like particles along a salinity gradient in a hypersaline coastal lagoon, Aquat. Microb. Ecol., 54, 171-183, doi:10.3354/Ame01262, 2009.

Schapira, M., Buscot, M. J., Pollet, T., Leterme, S. C., and Seuront, L.: Distribution of picophytoplankton communities from brackish to hypersaline waters in a South Australian coastal lagoon, Saline Systems, 6, doi:10.1186/1746-1448-6-2, 2010.

Seymour, J. R., Patten, N., Bourne, D. G., and Mitchell, J. G.: Spatial dynamics of virus-like particles and heterotrophic bacteria within a shallow coral reef system, Mar. Ecol.-Prog. Ser., 288, $1-8,2005$.

Soontharapirakkul, K., Promden, W., Yamada, N., Kageyama, H., Incharoensakdi, A., Iwamoto-Kihara, A., and Takabe, T.: Halotolerant Cyanobacterium Aphanothece halophytica Contains an Na+-dependent F1F0-ATP Synthase with a Potential Role in Salt-stress Tolerance, J. Biol. Chem., 286, 10169-10176, doi:10.1074/jbc.M110.208892, 2011.

Storey, J. D. and Tibshirani, R.: Statistical significance for genomewide studies, P. Natl. Acad. Sci. USA, 100, 9440-9445, doi:10.1073/pnas.1530509100, 2003.

Sun, S. L., Chen, J., Li, W. Z., Altintas, I., Lin, A., Peltier, S., Stocks, K., Allen, E. E., Ellisman, M., Grethe, J., and Wooley, J.: Community cyberinfrastructure for Advanced Microbial Ecology Research and Analysis: the CAMERA resource, Nucl. Acids Res., 39, D546-D551, doi:10.1093/nar/gkq1102, 2011.

Swan, B. K., Ehrhardt, C. J., Reifel, K. M., Moreno, L. I., and Valentine, D. L.: Archaeal and Bacterial Communities Respond Differently to Environmental Gradients in Anoxic Sediments of a California Hypersaline Lake, the Salton Sea, Appl. Environ. Microb., 76, 757-768, doi:10.1128/aem.02409-09, 2010.

Tyson, G. W., Chapman, J., Hugenholtz, P., Allen, E. E., Ram, R. J., Richardson, P. M., Solovyev, V. V., Rubin, E. M., Rokhsar, D. S., and Banfield, J. F.: Community structure and metabolism through reconstruction of microbial genomes from the environment, Nature, 428, 37-43, doi:10.1038/Nature02340, 2004

Welsh, D. T.: Ecological significance of compatible solute accumulation by micro-organisms: from single cells to global climate, FEMS Microbiol. Rev., 24, 263-290, doi:10.1111/j.15746976.2000.tb00542.x, 2000.

Wooley, J. C., Godzik, A., and Friedberg, I.: A primer on metagenomics, PLoS Comput. Biol., 6, e1000667, doi:10.1371/journal.pcbi.1000667, 2010.

Yale, J. and Bohnert, H. J.: Transcript Expression in Saccharomyces cerevisiae at High Salinity, J. Biol. Chem., 276, 15996-16007, doi:10.1074/jbc.M008209200, 2001. 